\title{
Glycated Haemoglobin and Outcomes of Percutaneous Coronary Intervention Among Type Two Diabetic Patients in Saudi Arabia
}

\author{
Saad Albugami ${ }^{1,2}$, Fahad Almehmadi ${ }^{3}$, Ziad M. Bukhari ${ }^{3}$, Mohammed S. Alqarni ${ }^{3}$, Abdulkarim W. \\ Abukhodair $^{3}$, Malak A. BinShihon ${ }^{3}$, Faisal Al-Husayni ${ }^{4}$, Razan A. Alhazzani ${ }^{3}$, Samah A. AlMatrafi ${ }^{3}$, \\ Khalid Makki ${ }^{5}$
}

1. Cardiology, King Abdullah International Medical Research Center, King Saud Bin Abdulaziz University for Health Sciences, Jeddah, SAU 2. Cardiology, King Faisal Cardiac Center, King Abdulaziz Medical City, Jeddah, SAU 3. Medicine, King Saud Bin Abdulaziz University for Health Sciences, Jeddah, SAU 4. Internal Medicine, King Abdulaziz Medical City, Jeddah, SAU 5. Cardiac Sciences, King Faisal Cardiac Center, King Abdulaziz Medical City, Jeddah, SAU

Corresponding author: Saad Albugami, sbugami@yahoo.com

\begin{abstract}
Background: Glycated haemoglobin (HbA1c) is a marker that reflects the control of diabetes mellitus (DM) over a three-month period. We sought to compare cardiovascular outcomes of diabetic patients with and without controlled levels of HbA1c post percutaneous coronary intervention (PCI) presenting to King Faisal Cardiac Center.
\end{abstract}

Methods: A retrospective single-center study of all patients with type two DM who were treated with PCI during the period between January 2015 and January 2018. All data were obtained from health informatics system. Demographics, clinical data, and major adverse cardiovascular and cerebrovascular events (MACCE) were collected to compare outcomes among diabetic patients with and without controlled $\mathrm{HbA1c}$.

Review began 10/08/2020 Review ended 10/31/2020 Published 10/31/2020

\section{(c) Copyright 2020}

Albugami et al. This is an open access article distributed under the terms of the Creative Commons Attribution License CC-BY 4.0., which permits unrestricted use, distribution, and reproduction in any medium, provided the original author and source are credited.
Results: The study included 177 patients with type two DM who underwent PCI. The mean age was 63.3 ( $\mathrm{SD} \pm 12$ ). Males represented $73.4 \%$ and $26.6 \%$ were females. The mean HbA1c on admission was $8.7 \%$. At presentation $31 \%$ of the patients had relatively controlled blood sugar (HbA1c mean $7.5 \%, \mathrm{SD} \pm 0.5$ ) and $69 \%$ presented with poorly controlled type two DM (mean HbA1c 9.1\%, SD \pm 0.25 ). The prevalence of hypertension and dyslipidaemia were higher among the uncontrolled group, but there were no differences between both groups in the control of blood pressure or dyslipidaemia. Patients in the uncontrolled group had higher rate of prior PCI (36.6\%) compared to the controlled arm (16\%, p=0.0195) The prevalence of cerebrovascular, cardiovascular, and renal impairment was similar. The use of insulin was higher among the uncontrolled arm. Patients in the controlled arm had lower incidence of composite endpoints of death and non-fatal myocardial infarction and stroke (MACCE) (14\% vs 41\%, p=0.001) compared to the uncontrolled arm.

Conclusion: Among patients with type two DM that were treated with PCI, achieving targets of blood sugar control reflected by glycated haemoglobin is associated with improved survival and lower incidence of composite MACCE.

Categories: Cardiology, Endocrinology/Diabetes/Metabolism

Keywords: percutaneous coronary intervention, diabetes mellitus, glycated haemoglobin, coronary artery disease, ischemic heart disease, coronary artery intervention, saudi arabia

\section{Introduction}

Coronary artery disease (CAD) is one of the deadliest diseases, killing around 7 million people annually $[1,2]$. Diabetes mellitus (DM) is a strong risk factor for CAD and is usually associated with a higher risk of mortality $[1,2]$. Diabetes mellitus is a global health issue that affects over 400 million adults worldwide. More than a million of them are in the Kingdom of Saudi Arabia (KSA) [3,4]. A report by the International Diabetes Federation states that in 2015, approximately 5 million diabetics died, and majority of these deaths were due to $\mathrm{CAD}$ [3]. Percutaneous coronary intervention (PCI) is widely available as a modality of therapy for patients with symptomatic CAD and many of them are diabetics. Studies show that the number of PCI is rising due to the inevitable trends of an increase in CAD risk factors which include DM $[5,6]$. Glycaemic control can impact the clinical outcome in diabetic patients after PCI. Several clinical studies found that admission hyperglycaemia (plasma glucose) is associated with increased short- and long-term mortality in diabetic patients with acute myocardial infarction [5-7]. However, acute myocardial infarction is frequently associated with abnormal glucose metabolism leading to hyperglycaemia due to stress-related catecholamines surge. Therefore, serum blood sugar measurements are unstable and unpredictable [7]. Glycated haemoglobin, haemoglobin A1c (HbA1c), is a marker that reflects the control of DM over a threemonth period and is hence considered a better prognostic marker of long-term outcome than other glucometabolic parameters reflecting exclusively fasting, postprandial, or incidental glycemia in patients with diabetes $[8,9]$. HbA1c has been found also to be an independent predictor of in-hospital mortality in ST- 
elevation myocardial infarction (STEMI) treated with primary PCI [8,9]. It is noteworthy that DM was found to be an independent predictor of mortality in the setting of non-ST-segment elevation acute coronary syndrome. Moreover, DM has been associated with worse outcomes following both percutaneous coronary intervention (PCI) and coronary artery bypass grafting (CABG) $[10,11]$. In Saudi Arabia, the baseline status, and subsequent results of PCI in diabetic patients with or without controlled glycated haemoglobin have not been well characterized. We aimed to assess the major adverse cardiac and cerebrovascular events (MACCE) among this group of patients who underwent PCI at King Faisal's Cardiac Center (KFCC) in Jeddah, Saudi Arabia.

\section{Materials And Methods}

This study is an observational retrospective cross-sectional study conducted at King Faisal Cardiac Center, Jeddah. The study included all consecutive patients with the confirmed diagnosis of type two DM with available glycated haemoglobin measurements who underwent percutaneous coronary intervention between January 2015 till December 2018. The inclusion criteria were age more than 18 years, treated with PCI, established diagnosis of type two DM, and available HbA1c measurement. Exclusion criteria were CABG as a method of revascularization during index hospitalization, lack of HbA1c measurement on presentation and follow-up, and type one DM.

Patients with available HbA1c at the time of PCI and at six months follow-up were divided into two groups; those with HbA1c $<7 \%$ at six months follow-up (controlled DM) and those with HbA1c $\geqslant 7 \%$ at six months follow-up (uncontrolled group). Our endpoints were the accumulative major adverse cardiac and cerebrovascular events, defined as death, nonfatal myocardial infarction (clinical presentation with acute coronary syndrome) and stroke. The data were collected from patients 'electronic files, including gender, age, date of procedure, medical history, laboratory values, pharmacological therapy and interventional treatment during index hospitalization and follow-up. The study was conducted following the Declaration of Helsinki. It received ethical approval from the Institutional Review Board of King Abdullah International Medical Research Center number IRBC/0266/19.

\section{Statistical analysis}

Participant's baseline characteristics were presented as means and standard deviations for continuous covariates, and as proportions for categorical covariates. Continuous covariates compared using two-sample t-test assuming normality of distributions under the Central Limit Theorem where categorical ones compared using Fisher's exact test. Time-to-event analysis for patients with controlled HbA1c (at follow-up $<7 \%$ ) to those who were uncontrolled ( $\mathrm{HbA1c} \geqslant 7 \%$ ) was performed using log-rank test. Univariate Coxregression performed to identify predictors of MACCE, and any variables with $p$-value of $<0.1$ (namely; $\mathrm{HbA1c} \geqslant 7 \%$, active smoking, use of dipeptidyl peptidase 4 [DPP-4] inhibitors, use of metformin, insulin use, total cholesterol level and body mass index) added to a multivariate model. Except for univariate coxregression covariate exploration, a two-sided p-value of $<0.05$ was considered to be significant. All statistical analyses were performed using R software version 4.0.0 (R Foundation for Statistical Computing, Vienna, Austria) [12].

\section{Results}

During the study period, 1218 patients had PCI and only 177 patients with type two DM had available glycated haemoglobin during index hospitalization and follow-up. The mean age was 63.2 years $\left(\mathrm{SD}^{ \pm} 12\right)$. Among the controlled group the mean age was 60.82 years $(\mathrm{SD} \pm 13.03)$ while in the uncontrolled arm was 64.3 ( $\mathrm{SD} \pm 11.33$ ) this was not significant $(\mathrm{p}=0.089$ ). The majority of patients were men $(73.4 \%)$. The mean glycated haemoglobin on presentation for the entire study patients was $8.7 \%\left(\mathrm{SD}^{ \pm} 1.9\right)$. In the controlled group the mean $\mathrm{HbA1c}$ was $7.56 \%$ (SD \pm 0.5 ) while among the uncontrolled group it was $9.19 \%$ ( $\mathrm{SD} \pm 0.25$, $\mathrm{p}<0.001)$.The uncontrolled group had significantly higher number of patients with hypertension $(86.9 \% \mathrm{vs}$ $63.4 \%, \mathrm{p}<0.00097)$, dyslipidemia $(69.7 \%$ vs $47.3 \%$, $\mathrm{p}<0.0068$ ) and prior coronary intervention ( $36.6 \%$ vs $16.4 \%, p<0.0195)$ though there were no significant differences in other associated conditions like smoking, prior stroke or obesity. The level of blood pressure and dyslipidaemia control was similar between both groups. Mean systolic blood pressure was $129 \mathrm{mmHg}$ ( $\mathrm{SD}^{ \pm 24}$ ) vs $133 \mathrm{mmHg}$ ( $\mathrm{SD}^{ \pm 19}$ ), $\mathrm{p}=0.363$, while the lowdensity lipoprotein was $2.38 \mathrm{mmole} / \mathrm{dl}\left(\mathrm{SD}^{ \pm} 0.89\right)$ vs $2.41 \mathrm{mmole} / \mathrm{dl}(\mathrm{SD} \pm 0.98), \mathrm{p}=0.818$. With regard to the pharmacological agents during the study period, there were no significant differences between both groups except for significantly higher use of insulin among the uncontrolled arm (68\% vs $30.9 \%, \mathrm{p}<0.0001)$ (Table 1$)$.

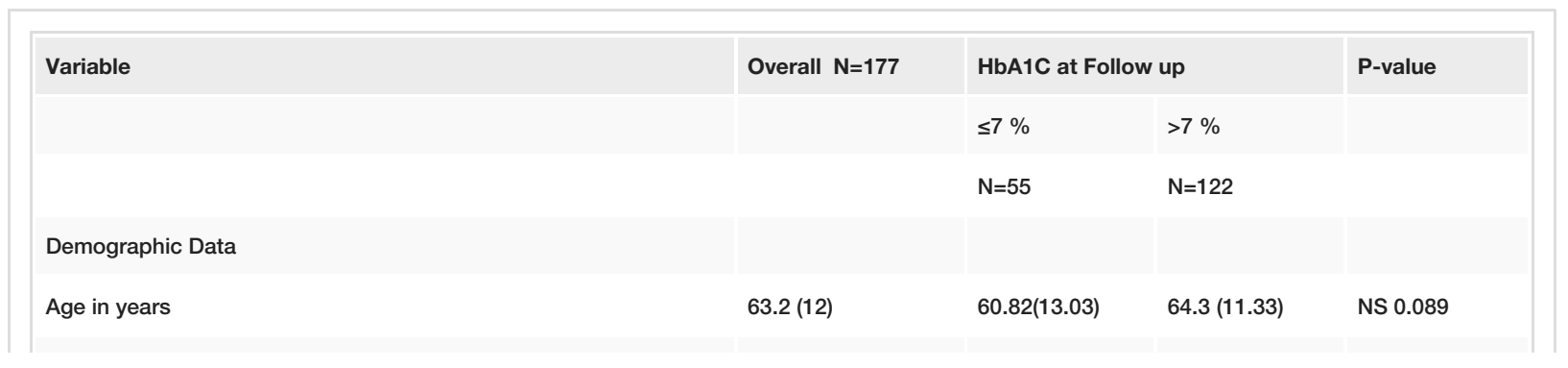




\section{Cureus}

\begin{tabular}{|c|c|c|c|c|}
\hline Male sex & $130(73.4)$ & $44(80)$ & $86(70.5)$ & NS 0.203 \\
\hline \multicolumn{5}{|l|}{ Medical Comorbidities } \\
\hline HbA1C level in \% at admission & $8.7(1.9)$ & $7.56(0.5)$ & $9.19(0.25)$ & $<0.001$ \\
\hline $\mathrm{HbA1C}$ level (change in follow up) in \% & $-0.03(1.87)$ & $-0.78(1.87)$ & $0.29(1.78)$ & $<0.001$ \\
\hline Hypertension & 141(79.9) & $35(63.4$ & 106(86.9) & $<0.00097$ \\
\hline Dyslipidaemia & $111(62.7)$ & $25(47.3)$ & $85(69.7)$ & 0.0068 \\
\hline Active smoking & $34(19.2)$ & $14(25.5)$ & 20(16.4) & NS 0.215 \\
\hline Body mass index in & $25.1(4.51)$ & 25.11(4.3) & $25.12(4.6)$ & NS 0.987 \\
\hline Prior Coronary intervention & $50(28.2)$ & $9(16.4)$ & $41(36.6)$ & 0.0195 \\
\hline Prior Coronary artery bypass grafting & 14(7.9) & $2(3.6)$ & 12(9.8) & NS 0.607 \\
\hline Documented three vessel disease & 7(4) & $1(1.8)$ & $6(4.9)$ & NS 0.32 \\
\hline Prior stroke & $8(4.5)$ & $2(3.6)$ & $6(4.9)$ & NS 0.687 \\
\hline \multicolumn{5}{|l|}{ Clinical Variables } \\
\hline Systolic blood Pressure (mmHg) & $132.4(20$ & 129(24) & 133(19) & NS 0.363 \\
\hline 17 Left Ventricular Ejection Fraction (\%) & $47.7(9.4)$ & 49.5(9.4) & 46.9(9.4) & NS 0.089 \\
\hline Creatinine Clearance, $(\mathrm{mL} / \mathrm{min} / 1.73 \mathrm{~m} 2)$ & 74.59(39) & $80(37)$ & $72(40)$ & NS 0.204 \\
\hline Total Cholesterol & $4.21(1.2)$ & $4.02(1.2)$ & $4.29(1.2)$ & NS 0.1614 \\
\hline Low-Density-lipoprotein (LDL) cholesterol & $2.4(0.94)$ & $2.38(0.89)$ & $2.41(0.98)$ & NS 0.818 \\
\hline High-Density-lipoprotein (HDL) cholesterol & $0.91(0.23)$ & $0.852(0.214)$ & $0.934(0.231)$ & 0.025 \\
\hline \multicolumn{5}{|l|}{ Medications } \\
\hline Aspirin * & $174(98.9)$ & $55(100)$ & 119(97.5) & NS 1 \\
\hline Minimum of 1 year of P2Y12 inhibitor ${ }^{*}$ & $174(98.9)$ & $54(98.2)$ & $116(95.1)$ & NS 1 \\
\hline High-dose Statin§ & 161(92) & 49(89.1) & 112(91.8) & NS 0.315 \\
\hline ACEI / ARB§ & $141(80.6)$ & $40(72.2)$ & 101(82.2) & NS 0.0936 \\
\hline Beta-blocker§ & 148(84.6) & $48(81.8)$ & 103(84.4) & NS 0.5 \\
\hline Mineralocorticoid inhibitor§ & $24(13.7)$ & $8(14.5)$ & 16(13.1) & NS 0.797 \\
\hline Sacubitril /Nalsartan§ & $1(<1)$ & $1(1.8)$ & $0(0)$ & NS 1 \\
\hline \multicolumn{5}{|l|}{ Anti-diabetic modalities } \\
\hline Metformin§ & 104(59.4) & $37(67.3)$ & $67(54.9)$ & NS 0.19 \\
\hline Sulfonylurea § & $41(54.7)$ & $12(21.8)$ & $30(24.6)$ & NS 0.6086 \\
\hline Insulin use § & $100(57.1)$ & $17(30.9)$ & $83(68)$ & $<0.0001$ \\
\hline Dipeptidyl Peptidase-4 (DPP-4) Inhibitor§ & $39(22.3)$ & 7(12.7) & $32(26.2)$ & NS 0.07319 \\
\hline Thiazolidinedione-type (TZD) § & $1(<1)$ & $0(0)$ & $1(<1)$ & NS 1 \\
\hline Acylated Glucagon-Like Peptide-1 (GLP-1) agonist & $7(3.9)$ & $2(3.6)$ & $5(4.1)$ & NS1 \\
\hline
\end{tabular}

TABLE 1: Demographics of the participants.

- Data are presented as Mean (Standard Deviation) for continuous variables or in proportions (\%) for categorical variables.

- Values were missing in two patients $\left(^{*}\right)$ for some covariates and three patients $(\S)$ for others.

$\mathrm{HbA1c}=$ haemoglobin A1c, ACEI = angiotensin-converting enzyme inhibitors, $\mathrm{ARB}=$ angiotensin receptor blocker 


\section{Cureus}

The composite endpoints of refractory angina, acute coronary syndrome, all-cause cardiovascular death and stroke was significantly higher among the uncontrolled arm (14\% vs 41.8\%, p<0.00036) (Table 2).

\begin{tabular}{|c|c|c|c|}
\hline & Controlled DM N= 55 & Uncontrolled DM $N=122$ & P value \\
\hline Retractory angina & $3(5.4 \%)$ & $18(14.7 \%)$ & \\
\hline Acute Coronary Syndrome & $4(7.2 \%)$ & $25(20.49 \%)$ & - \\
\hline Sudden Death & 0 & $3(2.4 \%)$ & - \\
\hline Cardiovascular mortality & $1(1.8 \%)$ & $3(2.4 \%)$ & - \\
\hline Stroke & 0 & $2(1.6 \%)$ & - \\
\hline Composite end points & $8(14 \%)$ & $51(41.8 \%)$ & 0.00036 \\
\hline
\end{tabular}

TABLE 2: Demonstrates the adverse cardiac and cerebrovascular events

$\mathrm{DM}=$ diabetes mellitus

Table 3 shows univariate Cox-regression analysis of covariates in predicting major cardiovascular events. On the analysis, factors that were associated with increased major adverse cardiovascular events (MACCE) were glycated haemoglobin level (odds ratio (OR) 2.96, 95\% confidence interval (CI) (1.5-5.86), $\mathrm{p}=0.00177$ ). Active smoking status, body mass index, cholesterol level, use of insulin, metformin and DPP-4 inhibitors. While on multivariate analysis glycated haemoglobin level was the only predictor of higher MACCE (OR $2.98,95 \% \mathrm{CI}(1.44-6.17), \mathrm{p}=0.00321)$ in addition to active smoking (OR 1.8937, 95\% CI (1.021-3.512), $\mathrm{p}=0.0428$ ) as demonstrated in Table 4. 


\section{Cureus}

\begin{tabular}{|c|c|c|c|c|}
\hline Covariate & Hazard Ratio & Lower $\mathrm{Cl}$ limit & Upper Cl limit & p-value \\
\hline $\mathrm{HbA1C}$ at entry & 2.16 & 1.06 & 4.41 & 0.0345 \\
\hline HbA1C during follow up & 2.96 & 1.5 & 5.86 & $0.00177^{\star} \S$ \\
\hline Change in HBA1C in follow up & 1.05 & 0.91 & 1.207 & 0.513 \\
\hline Age in years & 1 & 0.98 & 1.025 & 0.774 \\
\hline Body mass index & 0.94 & 0.89 & 1.007 & $0.0788^{\star}$ \\
\hline Dyslipidaemia & 1.4 & 0.86 & 2.59 & 0.151 \\
\hline Hypertension & 1.75 & 0.8 & 3.6 & 0.142 \\
\hline Prior coronary stenting & 1.007 & 0.574 & 1.766 & 0.982 \\
\hline Prior Coronary bypass & 1.306 & 0.5598 & 3.04 & 0.536 \\
\hline Prior Acute Coronary Syndrome & 1.525 & 0.759 & 3.015 & 0.245 \\
\hline Active smoking & 1.716 & 0.953 & 3.09 & $0.0722^{\star}$ \\
\hline Presence of 3 vessel disease & 1.56 & 0.488 & 4.99 & 0.452 \\
\hline Left Ventricular Ejection Fraction & 0.99 & 0.98 & 1.02 & 0.60 \\
\hline Creatinine Clearance & 0.944 & 0.986 & 1.00 & 0.17 \\
\hline Low-Density-lipoprotein (LDL) cholesterol & 1.159 & 0.8815 & 1.524 & 0.291 \\
\hline High-Density-lipoprotein (HDL) cholesterol & 1.23 & 0.39 & 3.85 & 0.723 \\
\hline Total Cholesterol & 1.209 & 0.984 & 1.1484 & $0.072^{\star}$ \\
\hline Use of ACEI/ ARB & 1.311 & 0.6 & 2.67 & 0.456 \\
\hline Use of High dose Statin & 1.484 & 0.527 & 4.176 & 0.445 \\
\hline Use of Dipeptidyl Peptidase-4 (DPP-4) Inhibitor & 0.536 & 0.26 & 1.093 & $0.086^{*}$ \\
\hline Use of Sulfonylurea & 0.7484 & 0.388 & 1.443 & 0.387 \\
\hline Insulin use & 1.59 & 0.92 & 2.755 & $0.092^{\star}$ \\
\hline Use of Metformin & 0.505 & 0.3012 & 0.8467 & $0.00956^{*}$ \\
\hline
\end{tabular}

TABLE 3: Univariate Cox-regression analysis of covariates in predicting major cardiovascular events.

* Covariates with $\mathrm{p}$-value $\leq 0.1$ included in multivariate analysis.

$\S$ We chose the follow-up HbA1c as it is more indicative of medical therapy adequacy after the index event.

$\mathrm{HbA1c}=$ haemoglobin A1c, ACEI = angiotensin-converting enzyme inhibitors, $\mathrm{ARB}=$ angiotensin receptor blocker 


\section{Cureus}

\begin{tabular}{|c|c|c|c|c|}
\hline Covariate & Hazard Ratio & Lower $\mathrm{Cl}$ limit & Upper Cl limit & p-value \\
\hline HbA1C > 7\% at follow-up & 2.98 & 1.44 & 6.17 & $0.00321^{\star}$ \\
\hline Use of Dipeptidyl Peptidase-4 (DPP-4) Inhibitor & 0.55 & 0.26 & 1.14 & 0.108 \\
\hline Insulin use & 1.06 & 0.57 & 1.97 & 0.853 \\
\hline Use of Metformin & 0.65 & 0.365 & 1.15 & 0.138 \\
\hline Total Cholesterol & 1.13 & 0.91 & 1.42 & 0.272 \\
\hline Active smoking & 1.82 & 0.981 & 3.38 & 0.0577 \\
\hline Body mass index (BMI) & 0.96 & 0.91 & 1.03 & 0.245 \\
\hline
\end{tabular}

TABLE 4: Multivariate Cox-regression analysis of covariates in predicting major cardiovascular events. (Final model included the following covariates: HbA1c at follow-up, use of insulin, use of DPP-4 inhibitor, use of metformin, BMI, total cholesterol, and active smoking.)

$\mathrm{HbA1c}=$ haemoglobin A1c

Figure 1 shows the Kaplan Mayer curves which demonstrates the effects of higher glycated haemoglobin post-PCI and the increased mortality that was associated with poor HbA1c control.

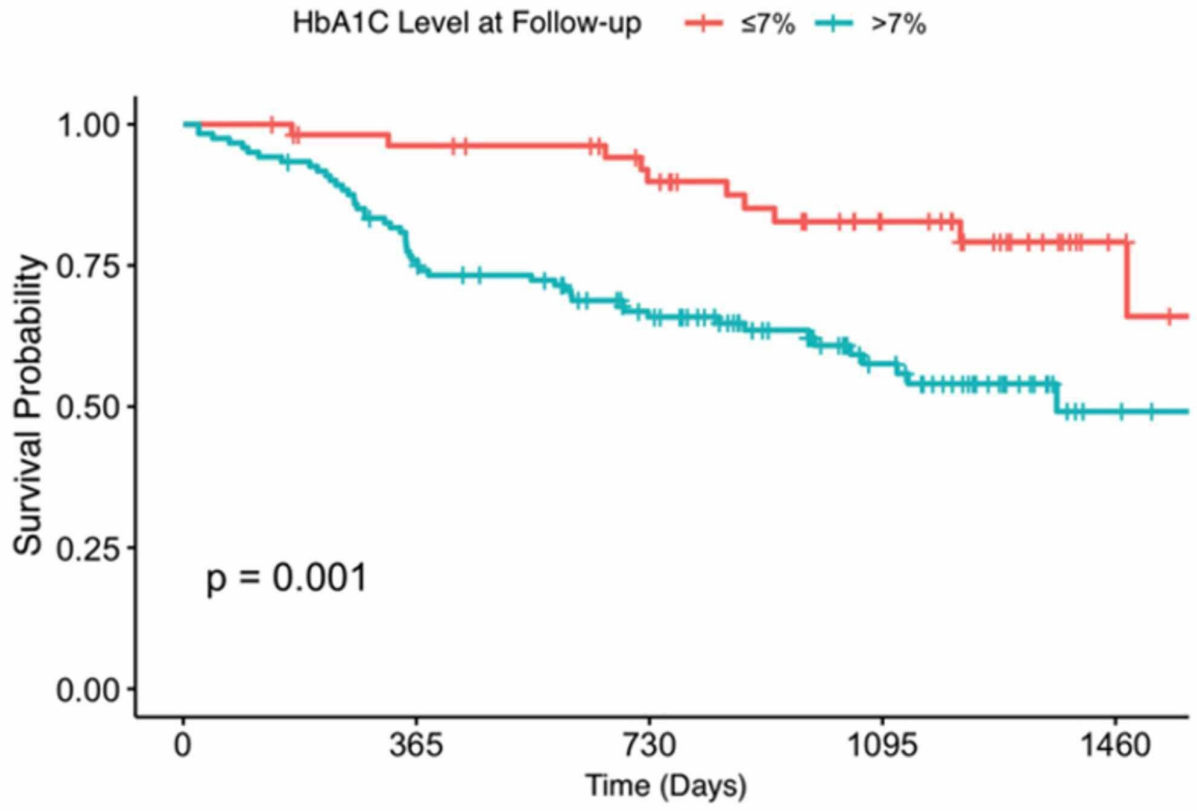

\section{Risk Set}

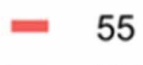

121
50

90
42

67
27

34
7

7

FIGURE 1: Kaplan-Meier curves showing event-free survival of each HbA1c.

$\mathrm{HbA1c}=$ haemoglobin A1c

Patients who maintain or achieve guideline recommended $\mathrm{HbA} 1 \mathrm{c}$ of less than $7 \%$ have improved survival while those who either continue to have high levels or lose adequate control and or never achieve HbA1c of less than $7 \%$ at follow up have higher rate of mortality (Figure 2). 


\section{Cureus}

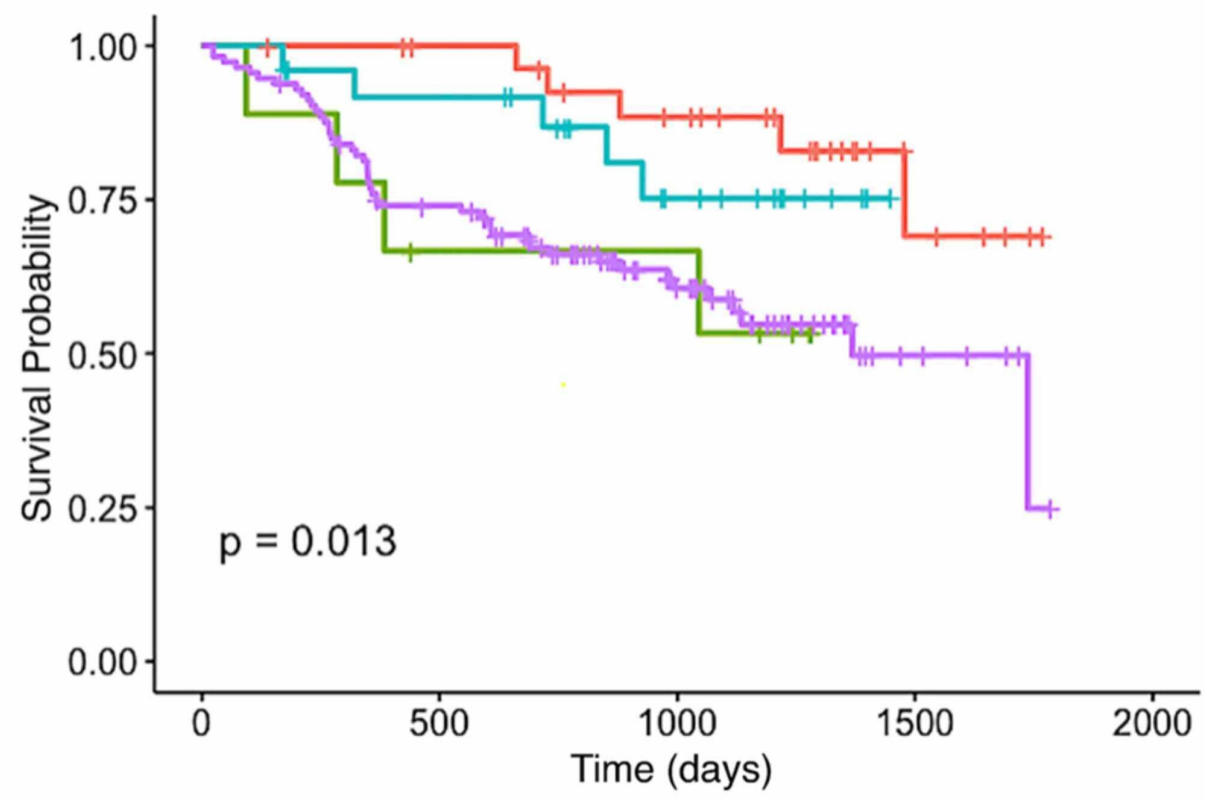

\footnotetext{
Controlled throughout "Hbaic sTs throughout the follow up"

- Regained Control " HbAIC $>7 \%$ carly to $\leq 7 \%$ during follow up"

Lost Control "HbAIC $\leq 7 \%$ early to $>7 \%$ during follow up"

-1 Uncontrolled throughout "НЬАІС $>7 \%$ throughout the follow up"
}

FIGURE 2: Kaplan-Meier curves showing event-free survival probability based on the change of $\mathrm{HbA1c}$ status during follow-up period.

$\mathrm{HbA1c}=$ haemoglobin A1c

\section{Discussion}

The overall prevalence of CAD as assessed by various diagnostic methods is as high as $55 \%$ among adult patients with DM, compared with 2 to $4 \%$ in the general population [13-18]. It is considered an independent risk factor for increased mortality and morbidity [13-18]. The cardiovascular mortality rate is more than doubled in men and more than quadrupled in women who have DM, compared with their non-diabetic counterparts [14-15]. DM is a recognized risk factor for poor outcome following either percutaneous coronary or surgical revascularization [15-18]. In Saudi Arabia, the prevalence of diabetes among ACS patients is $56 \%$ as reported previously $[19,20]$. Those patients are more likely to present with non-STelevation myocardial infarction (NSTEMI) or unstable angina compared to non-diabetic patients (40.2\% vs $31.4 \%$, and $22.6 \%$ vs $21.1 \%$, respectively), and less likely to present with STEMI ( $37.2 \%$ vs $47.5 \%$; $\mathrm{p}=0.001$ ) as reported by AlNemer et al. In addition, they have a higher rate of major adverse cardiovascular outcomes [21].

Many randomized clinical trials have demonstrated that therapies that improve glycaemic control decrease the risk of microvascular disease, including retinopathy, nephropathy, and neuropathy [22]. However, trials attempting to decrease macrovascular events have been unsuccessful [23-25], improved glycaemic control showed no reduction in the rate of cardiovascular events and in the Action to Control Cardiovascular Risk in Diabetes (ACCORD) trial [23], it was associated with increased risks of death from any cause and death from cardiovascular events.

A breakthrough in the management of patients with type two DM at high risk for cardiovascular events was reported by Zinman and colleagues [26] with the use of empagliflozin which demonstrated a reduction in the rate of the primary composite cardiovascular outcome and of death from any cause when the study drug was added to standard care. The adjusted mean differences in the glycated haemoglobin level between patients receiving empagliflozin and those receiving placebo were -0.54 percentage points $(95 \% \mathrm{CI},-0.58$ to -0.49$)$ in the $10 \mathrm{mg}$ group and -0.60 percentage points ( $95 \% \mathrm{CI},-0.64$ to -0.55 ) in the $25 \mathrm{mg}$ group, although many patients did not reach their glycaemic targets, with an adjusted mean glycated haemoglobin level at week 206 of $7.81 \%$ in the pooled empagliflozin group and $8.16 \%$ in the placebo group.

Our single-center retrospective study has demonstrated the favourable effect of maintaining and achieving 
the guideline-recommended level of HbA1c in diabetic patients post-PCI. The composite endpoints of MACCE were statistically better among patients with controlled HbA1c levels at follow-up. Although there were statistically significant differences between both groups as the uncontrolled arm had a higher rate of hypertension and dyslipidaemia, there was however no difference in the level of control of these two risk factors, the facts that the uncontrolled group had a higher rate of use of medication, especially insulin, would suggest the heightened efforts to control DM or might reflect advanced DM.

The results of our study are consistent with what was previously reported by Kessaian and colleagues [27] where they have reported that diabetics with poor glycaemic control based on levels of HbA1c are at two-fold higher risk of developing MACCE following PCI. Other investigators [8-28] have also observed lower rates of target vessel revascularization (TVR), cardiac rehospitalization and recurrent angina in optimally controlled $($ HbA1c $\leqslant 7 \%)$ in diabetic patients.

However other studies have examined the potential association between HbA1c and clinical outcomes among DM patients after PCI, these studies were inconclusive and sometimes even contradictory, due to the fact that the majority of these studies were small-sized, leading to inadequate statistical power. A recent large meta-analysis by Zheng et al. [29] demonstrated that high blood HbA1c levels might be associated with higher risks of target vessel revascularization, progression of CAD, and nonfatal myocardial infarction among diabetic patients after PCI.

We have noted that other factors can be significantly associated with increased MACCE among diabetic patients, namely smoking, obesity, use of insulin, and DDP-4 inhibitors. When controlling for other variables, active smoking and HbA1c were the only predictors for increased MACCE in our study.

To the best of our knowledge, this is the first study in the Saudi population that assessed the post-procedural impact of HbA1c control following PCI and MACCE. A large, prospective, and multicentre study is underway.

\section{Limitations}

Our study has many limitations, it is retrospective therefore it has an inherent selection bias as many patients who were treated by PCI were excluded due to lack of HbA1c level on presentation and follow-up. It's a single-center study, which may affect generalizability of its conclusion. We also did not assess the duration of DM and the indications for revascularization whether this is done due to an acute coronary syndrome or as an elective procedure for chronic angina. Another limitation is the small number of patients. Yet the results provided reflect data consistent with other studies linking poor outcomes of patients with coronary artery disease and uncontrolled DM.

\section{Conclusions}

Patients with coronary artery disease and uncontrolled DM reflected by HbA1c above 7\% at or during followup have an increased rate of death and non-fatal MI compared to patients who maintain or achieve guidelines recommended HbA1c of less than $7 \%$. Large and multicentre studies are required to further ascertain this finding. Guidelines recommending control of type two DM will favourably improve long-term outcomes of coronary artery disease.

\section{Additional Information \\ Disclosures}

Human subjects: Consent was obtained by all participants in this study. King Abdullah International Medical Research Center issued approval IRBC/0266/19. Animal subjects: All authors have confirmed that this study did not involve animal subjects or tissue. Conflicts of interest: In compliance with the ICMJE uniform disclosure form, all authors declare the following: Payment/services info: All authors have declared that no financial support was received from any organization for the submitted work. Financial relationships: All authors have declared that they have no financial relationships at present or within the previous three years with any organizations that might have an interest in the submitted work. Other relationships: All authors have declared that there are no other relationships or activities that could appear to have influenced the submitted work.

\section{Acknowledgements}

We would like to thank all the staff of King Faisal Cardiac Center and the department of medical records at the King Abdulaziz Medical City in Jeddah.

\section{References}

1. Aronson D, Edelman ER: Coronary artery disease and diabetes mellitus . Cardiol Clinics. 2014, 32:439-455. 10.1016/j.ccl.2014.04.001

2. Heart Disease Facts and Statistics. (2018). Accessed: January 2020 https://www.cdc.gov/heartdisease/facts.htm.

3. Diabetes Federation: Diabetes and Cardiovascular Disease Executive Summary. International Diabetes 
Federation, Brussels; 2016.

4. Health Days 2016. (2018). Accessed: January 2020:

https://www.moh.gov.sa/en/healthawareness/healthday/2016/pages/healthday-2016-11-14.aspx.

5. Berry C, Nobel S, Gregoire JC, Ibrahim R, Levesquie MA, L’Allier PL, Tardif JC: Glycemic status influences the nature and severity of coronary artery disease. Diabetologia. 2010, 53:652-658. 10.1007/s00125-0091651-x

6. Sharma PK, Agrawal S, Ellis SG, et al.: Association of glycaemic control with mortality in patients with diabetes mellitus undergoing percutaneous coronary intervention. Circ Cardiovasc Interv. 2014, 7:503-509. 10.1161/CIRCINTERVENTIONS.116.004157

7. Ishihara M, Kagawa E, Inoue I, et al.: Impact of admission hyperglycaemia and diabetes mellitus on shortand long-term mortality after acute myocardial infarction in the coronary intervention era. Am J Cardiol. 2007, 99:1674-1679. 10.1016/j.amjcard.2007.01.044

8. Corpus RA, George PB, House JA, et al.: Optimal glycemic control is associated with a lower rate of target vessel revascularization in treated type II diabetic patients undergoing elective percutaneous coronary intervention. J Am Coll Cardiol. 2004, 43:8-14. 10.1016/j.jacc.2003.06.019

9. Kowalczyk J, Mazurek M, Zielinska T, et al.: Prognostic significance of HbA1c in patients with AMI treated invasively and newly detected glucose abnormalities. Eur J Prevent Cardiol. 2015, 22:798-806. $10.1177 / 2047487314527850$

10. Marso SP, Giorgi LV, Johnson WL, et al.: Diabetes mellitus is associated with a shift in the temporal risk profile of in-hospital death after percutaneous coronary intervention: an analysis of 25,223 patients over 20 years. Am Heart J. 2003, 145:270-7. 10.1067/mhj.2003.56

11. Roffi M, Topol EJ: Percutaneous coronary intervention in diabetic patients with non-ST-segment elevation acute coronary syndromes. Eur Heart J. 2004, 25:190-8. 10.1016/j.ehj.2003.10.027

12. R: A Language and Environment for Statistical Computing. R Foundation for Statistical Computing, Vienna, Austria. (2020). https://www.r-project.org/.

13. Stamler J, Vaccaro O, Neaton JD, Wentworth D: Diabetes, other risk factors, and 12-yr cardiovascular mortality for men screened in the multiple risk factor intervention trial. Diabetes Care. 1993, 16:434-44. 10.2337/diacare.16.2.434

14. Wingard DL, Barrett-Connor E: Heart disease and diabetes. Nat Diabet Data Group. 1995, 429-48.

15. Woodfield SL, Lundergan CF, Reiner JS, et al.: Angiographic findings, and outcome in diabetic -patients treated with thrombolytic therapy for acute myocardial infarction: the GUSTO-I experience. J Am Coll Cardiol. 1996, 28:1661-9. 10.1016/S0735-1097(96)00397-X

16. Zuanetti G, Latini R, Maggioni AP, Santoro L, Franzosi PG, for the GISSI-2 Investigators: Influence of diabetes on mortality in acute myocardial infarction: data from the GISSI-2 study. J Am Coll Cardiol. 1993, 22:1788-94. 10.1016/0735-1097(93)90758-s

17. The Bypass Angioplasty Revascularization Investigation (BARI) Investigators: Comparison of coronary bypass surgery with angioplasty in patients with multivessel disease. N Engl J Med. 1996, 335:217-25. 10.1056/NEJM199607253350401

18. Weintraub WS, Stein B, Kosinski A, et al.: Outcome of coronary bypass surgery versus coronary angioplasty in diabetic patients with multivessel coronary artery disease. J Am Coll Cardiol. 1998, 31:10-9. 10.1016/s0735-1097(97)00441-5

19. El-Menyar A, Zubaid M, Shehab A, et al.: Prevalence and impact of cardiovascular risk factors among patients presenting with acute coronary syndrome in the Middle East. Clin Cardiol. 2011, 34:51-58. 10.1002/clc. 20873

20. AlHabib KF, Hersi A, AlFaleh H, et al.: The Saudi Project for Assessment of Coronary Events (SPACE) registry: design and results of a phase I pilot study. Can J Cardiol. 2009, 25:e255-e258. 10.1016/s0828282x(09)70513-6

21. Khalid A, AlNemer H, AlFaleh KF, et al.: Impact of diabetes on hospital adverse cardiovascular outcomes in acute coronary syndrome patients: Data from the Saudi project of acute coronary events. J Saudi Heart Assoc. 2012, 24:225-231. 10.1016/j.jsha.2012.08.002

22. UK Prospective Diabetes Study (UKPDS) Group: Intensive blood-glucose control with sulphonylureas or insulin compared with conventional treatment and risk of complications in patients with type 2 diabetes (UKPDS 33).UK Prospective Diabetes Study (UKPDS) Group. Lancet. 1998, 352:837-853. 10.1016/S01406736(98)07019-6

23. Gerstein HC, Miller ME, Byington RP, et al.: Effects of intensive glucose lowering in type 2 diabetes . N Engl J Med. 2008, 358:2545-2559. 10.1056/NEJMoa0802743

24. Patel A, MacMahon S, Chalmers J, et al.: Intensive blood glucose control and vascular outcomes in patients with type 2 diabetes. N Engl J Med. 2008, 358:2560-2572. 10.1056/NEJMoa0802987

25. Duckworth W, Abraira C, Moritz T, et al.: Glucose control and vascular complications in veterans with type 2 diabetes. N Engl J Med. 2009, 360:129-139. 10.1056/NEJMoa0808431

26. Zinman B, Wanner C, Lachin JM, et al.: Empagliflozin, cardiovascular outcomes, and mortality in type 2 diabetes. N Engl J Med. 2015, 373:2117-2128. 10.1056/NEJMoa1504720

27. Kassaian S, Goodarzynejad H, Boroumand M, et al.: Glycosylated hemoglobin (HbA1c) levels and clinical outcomes in diabetic patients following coronary artery stenting. Cardiovasc Diabetol. 2012, 11:82. 10.1186/1475-2840-11-82

28. Briguori C, Condorelli G, Airoldi F, Mikhail GW, Ricciardelli B, Colombo A: Impact of Glycemic and lipid control on outcome after percutaneous coronary interventions in diabetic patients. Heart. 2004, 90:14811482. 10.1186/1475-2840-11-82

29. Zheng J, Cheng J, Zhang Q, Qi C, Wang T, Xiao X: Association between glycosylated hemoglobin level and cardiovascular outcomes in diabetic patients after percutaneous coronary intervention. Medicine. 2016, 95:10.1097/MD.0000000000003696 